\title{
In This Issue: Developing and Amplifying the Effective- ness of the Primary Care Workforce
}

\author{
Kurt C. Stange, $M D, P b D$, Editor \\ Ann Fam Med 2015;13:102-103. doi: 10.1370/afm.1769.
}

I

$\mathrm{n}$ addition to a number of interesting clinical

research studies and reflections, articles in this issue

illuminate how the primary care workforce can be expanded and made more effective.

A shortage of primary care physicians and a shortfall in production rates is projected in analyses by Liaw and colleagues. ${ }^{1}$ Changing care delivery models toward small panel sizes substantially increases the shortage.

Willard-Grace et al show how the effectiveness of the primary care workforce can be enhanced by involving medical assistants as in-office health coaches. ${ }^{2}$ Medical assistant health coaches are effective in helping patients to meet goals for diabetes control and cholesterol reduction, but not blood pressure treatment. This article is this issue's Annals Journal Club. ${ }^{3}$

Social networks within primary care practices, in terms of the density of interactions among team members, are associated with fewer hospital days and lower medical care costs for patients with cardiovascular disease, according to a study by Mundt and colleagues. ${ }^{4}$ This important relationship is mediated by the team's degree of shared vision about goals and expectations.

For those evaluating change toward the patientcentered medical home, Goldman and colleagues provide a mixed methods roadmap that examines both patient and practice processes and outcomes. ${ }^{5}$

Jackson and colleagues provide information to guide how we arrange follow-up of patients to reduce hospital readmissions. ${ }^{6}$ They find that most patients do not benefit from early outpatient follow-up, and they identify a subgroup based on multimorbidity and risk that may benefit from early hospital follow-up.

A study of a large sample of older people with multiple medical conditions finds that continuity of care is associated with lower rates of hospital use, even in an integrated delivery system with shared electronic medical records that provide continuity of information to different health care providers. ${ }^{7}$

Another study of patients with multiple chronic medical conditions, by Mercer and colleagues, finds that multimorbidity is strongly associated with hospi- talization across 3 widely different health care systems, but the relationship between socioeconomic deprivation, multimorbidity, and hospital admission varies across different systems in ways that give insights into how systems might be made equitable and effective. ${ }^{8}$

Inviting people to be screened for type 2 diabetes turns out to have a limited effect on cardiovascular morbidity, self-rated health, or health behavior after 7 years of follow-up, in a study by Griffin and colleagues. ${ }^{9}$

A longitudinal study of chronic abdominal pain in children finds that pain persists for at least 1 year in one-third of children. The study identifies some modestly useful but practical predictors of persistent pain. ${ }^{10}$

Two essays hit hard with personal reflections on challenging interpersonal relationships. Vidal asks why medical schools tolerate unethical behavior by their faculty ${ }^{11}$ and Hughes shares her personal struggle after witnessing a man commit suicide. ${ }^{12}$

Finally, a pair of Point-Counterpoint articles argue the question: is secondhand smoke exposure a form of child abuse? ? $^{13,14}$

We welcome your reflections at http://www. AnnFamMed.org.

\section{References}

1. Petterson SM, Liaw WR, Tran C, Bazemore AW. Estimating the residency expansion required to avoid projected primary care physician shortages by 2035. Ann Fam Med. 2015;13(2):107-114.

2. Willard-Grace $R$, Chen EH, Hessler D, et al. Health coaching by medical assistants to improve control of diabetes, hypertension, and hyperlipidemia in low-income patients: a randomized controlled trial. Ann Fam Med. 2015;13(2):130-138.

3. Rohrberg T. Annals Journal Club. Impact of medical assistants as health coaches. Ann Fam Med. 2015;13(2):iii.

4. Mundt MP, Gilchrist VJ, Fleming MF, Zakletskaia LI, Tuan W-J, Beasley JW. Effects of primary care team social networks on quality of care and costs for patients with cardiovascular disease. Ann Fam Med. 2015;13(2):139-148.

5. Goldman RE, Parker DR, Brown J, Walker J, Eaton CB, Borkan JM. Recommendations for a mixed methods approach to evaluating the patient-centered medical home. Ann Fam Med. 2015;13(2):168-175.

6. Jackson C, Shahsahebi M, Wedlake T, DuBard CA. Timeliness of outpatient follow-up: an evidence-based approach for planning after hospital discharge. Ann Fam Med. 2015;13(2):115-122. 
7. Bayliss EA, Ellis JL, Shoup J, Zeng C, McQuillan DB, Steiner JF. Effect of continuity of care on hospital utilization for seniors with multiple medical conditions in an integrated health care system. Ann Fam Med. 2015;13(2):123-129.

8. Wang HHX, Wang JJ, Lawson KD, et al. Relationships of multimorbidity and income with hospital admissions in 3 health care systems. Ann Fam Med. 2015;13(2):164-167.

9. Echouffo-Tcheugui JB, Simmons RK, Prevost AT, et al. Long-term effect of population screening for diabetes on cardiovascular morbidity, self-rated health, and health behavior. Ann Fam Med. 2015;13(2):149-157.
10. Spee LAA, Lisman-van Leeuwen Y, Benninga MA, Bierma-Zeinstra SMA, Kollen BJ, Berger MY. Predictors of chronic abdominal pain affecting the well-being of children in primary care. Ann Fam Med. 2015;13(2):158-163.

11. de Oliveira Vidal El, dos Santos Silva V, dos Santos MF, Jacinto AF, Villas Boas PJF, Fukushima FB. Why medical schools are tolerant of unethical behavior. Ann Fam Med. 2015;13(2):176-180.

12. Hughes LS. You can't hide the bridges. Ann Fam Med. 2015;13(2): 181-183.

13. Goldstein AO. Is exposure to secondhand smoke child abuse? Yes. Ann Fam Med. 2015;13(2):103-104.

14. Lindhorst T. Is exposure to secondhand smoke child abuse? No. Ann Fam Med. 2015;13(2):105-106.

\title{
POINT I COUNTERPOINT
}

\section{Is Exposure to Secondhand Smoke Child Abuse? Yes.}

\author{
Adam O. Goldstein, MD, MPH \\ Department of Family Medicine, University of North Carolina at Chapel Hill School of Medicine
}

Ann Fam Med 2015;13:103-104. doi: 10.1370/afm.1764.

S cientific research over the last decade has increasingly demonstrated that exposure to secondhand smoke is not simply a nuisance, it is deadly. ${ }^{1}$ Secondhand smoke exposure causes multiple diseases in children, including asthma and pneumonia, and results in thousands of avoidable hospitalizations. ${ }^{2}$ Secondhand smoke exposure is a major cause of sudden infant death syndrome and may cause lung cancer and heart attacks with repeated exposure. ${ }^{2}$ No safe level of exposure exists. ${ }^{1,2}$

Purposefully and recurrently exposing children to secondhand smoke - a known human carcinogendespite repeated warnings, is child abuse. Federal law defines child abuse as "any recent act or failure to act on the part of a parent or caretaker which results in death, serious physical or emotional harm, sexual abuse or exploitation; or an act or failure to act which presents an imminent risk of serious barm." In the case presented below, our patient's parents failed to act in a way to remove

Conflict of interest: author reports none.

\section{CORRESPONDING AUTHOR}

Adam O. Goldstein, MD, MPH

Department of Family Medicine

Director Tobacco Intervention Programs

UNC School of Medicine

Chapel Hill NC 27599-7595

aog@med.unc.edu their child from recurring, life-threatening harm by secondhand smoke, thereby constituting child abuse.

\section{Case}

At least 10 times over 3 years, we counseled the family to quit smoking around the 5 -year-old patient and her 7-year-old sister, as the kids repeatedly came to the clinic for ear infections, coughing, bronchitis, and asthma. Two months after a recent visit, the younger child developed pneumonia. We successfully treated her with antibiotics and inhalers, and gave strong admonitions to the parents to avoid smoking anywhere near the children, offering the parents detailed counseling support. The parents, however, refused to engage with us about quitting smoking, pharmacotherapy for cessation, or about not letting their children be exposed to cigarette smoke.

In the clinic, the residents and I discussed the case in detail, asking ourselves what more we could do. We reviewed the Public Health Service guidelines on tobacco use treatment that document optimal ways to help people quit smoking, then reviewed our attempts at counseling and referral and the quality improvement efforts in our office systems to support improved outcomes. ${ }^{4}$ In short, we did everything that evidencebased guidelines tell us to do.

We still did not do enough. Not long after, the younger child showed up in the emergency room with a recurrence of pneumonia and severe asthma. By the 